\title{
Anabases
}

ANABASES Traditions et réceptions de l'Antiquité

13 | 2011

Varia

\section{Le brigandage à l'époque moderne : approches méthodologiques}

\section{Valérie Sottocasa}

\section{(2) OpenEdition}

1 Journals

Édition électronique

URL : http://journals.openedition.org/anabases/1890

DOI : 10.4000/anabases. 1890

ISSN : 2256-9421

Éditeur

E.R.A.S.M.E.

\section{Édition imprimée}

Date de publication : 1 mars 2011

Pagination : 247-252

ISSN : 1774-4296

\section{Référence électronique}

Valérie Sottocasa, "Le brigandage à l'époque moderne : approches méthodologiques », Anabases [En ligne], 13 | 2011, mis en ligne le 01 mars 2014, consulté le 20 octobre 2019. URL : http:// journals.openedition.org/anabases/1890 ; DOI : 10.4000/anabases.1890

Ce document a été généré automatiquement le 20 octobre 2019.

(c) Anabases 


\title{
Le brigandage à l'époque moderne : approches méthodologiques
}

\author{
Valérie Sottocasa
}

\section{NOTE DE L'ÉDITEUR}

Le comité de rédaction d'Anabases remercie vivement Valérie Sottocasa, spécialiste de l'histoire du brigandage à l'époque moderne, d'avoir bien voulu se prêter à l'expérience du comparatisme.

1 Qui sont les brigands de l'époque moderne? Quelques figures emblématiques s'imposent, tel Cartouche, le voleur parisien, ou Mandrin, le brigand contrebandier. Des légendes locales ont également marqué la littérature populaire et régionale, Gaspard de Besse en Provence, Roux le bandit en Cévennes, Marion du Faouet en Bretagne et tant d'autres encore. Au-delà de ces grandes figures, les sources de justice et de police attestent l'existence d'une criminalité organisée autour de bandes, constitutive du brigandage sous l'Ancien régime et la Révolution, mais sans jamais formuler précisément les caractères de cette forme de délinquance. Les dictionnaires de l'époque moderne insistent sur plusieurs points, notamment l'association en bandes armées et le vol sur les grands chemins. Les brigands officient à la campagne plus que dans les villes, et si Cartouche est parfois qualifié de brigand, c'est sans doute parce qu'il est à la tête d'une bande redoutablement efficace. Les dictionnaires, notamment celui de Furetière ${ }^{1}$, soulignent l'origine militaire du brigandage qui rassemblerait «des soldats mal disciplinés qui ne font que piller et désoler les pays où ils font des courses ». L'origine du mot remonte, selon l'auteur, aux soldats que la ville de Paris avait armés en 1356, pendant la guerre de Cent Ans et la détention du roi Jean. On leur aurait donné ce nom à cause des « brigandines » dont ils étaient équipés et qui étaient des armes communes à cette époque. Le même dictionnaire souligne une autre étymologie, inspirée d'une bande de voleurs allemands de la région du lac de Constance qui se seraient appelés «brigantins ». 
2 D'autres dictionnaires attribuent au mot «brigand» une origine italienne: briga signifie bande en italien; «brigante» serait apparu dans la langue italienne en $1410^{2}$. Le dictionnaire de Trévoux, paru en 1704 et réédité jusqu'en 1771, reprend la définition donnée par Furetière un siècle plus tôt pour «brigand » et ajoute celle de «bandit »: «Exilé, voleur, assassin qui court le païs à main armée [...] ${ }^{3}$.» À leur manière, les gravures de Jacques Callot sur les malheurs de la guerre nous renseignent sur la représentation que se font les contemporains de la guerre de Trente Ans des brigands, figurés en soldats se livrant au pillage ${ }^{4}$. Loin d'être anodin, l'ancrage des brigands dans des bandes armées est un facteur aggravant dans la qualification judiciaire du crime. Qu'il s'agisse de la bande montée par Cartouche au début du XviII ${ }^{e}$ siècle ${ }^{5}$, de celle d'Orgères, qui sévit dans l'Eure pendant la Révolution ou encore de celle de Pourrières (Var), démantelée en l'an XI, toute association criminelle menace gravement l'ordre public. L'usage de la violence, le caractère implacable de ces hommes, étrangers à la morale sociale, leur maîtrise des espaces sauvages (bois, montagnes, cavernes) et de la nuit, en font des ennemis du genre humain. L'organisation des bandes agite le spectre de contre-sociétés destinées à détruire l'ordre. L'évolution de la législation et de la répression du brigandage témoigne d'un souci croissant, de la part des autorités, à lutter contre cette menace avec toujours plus d'efficacité. Il n'empêche: si le brigandage de grand chemin semble décliner dans la seconde moitié du XVIII ${ }^{\mathrm{e}}$ siècle, le phénomène est à l'origine de la Grande Peur de l'été 1789 et connaît une nouvelle vitalité au lendemain de la réaction royaliste qui suit la chute de Robespierre en 1794. Il faut toute l'énergie de la police, de la gendarmerie et des Préfets de l'Empire pour y mettre fin, de manière d'ailleurs relative.

L'histoire du brigandage a longtemps semblé relever davantage de la littérature populaire que de l'histoire politique et sociale. Au xix siècle, les histoires de brigands font plus appel à l'imagination qu'à la lecture des sources judiciaires et administratives. Leurs objectifs relèvent de la morale plus que de l'analyse historique. Au début du $\mathrm{xx}^{\mathrm{e}}$ siècle, plusieurs ouvrages tentent une approche plus historique du brigandage en tant que phénomène social. Les études portant sur Mandrin et Cartouche suscitent toujours beaucoup d'intérêt, mais l'approche du brigandage commence à dépasser l'intérêt pour les hommes célèbres et les légendes locales ${ }^{6}$. En 1934, Marcel Marion publie une histoire du brigandage sous la Révolution ${ }^{7}$. Certes, son étude n'est pas dénuée d'une dimension morale et surtout hagiographique en faveur de l'Empire, mais son ouvrage inscrit le brigandage dans une perspective historique donnant toute son importance au contexte particulier de la Révolution. Tout comme Taine quelques décennies plus tôt, il brosse le tableau d'un brigandage qui serait le fruit de l'anarchie provoquée par la Révolution et plus particulièrement par la République. C'est cependant à la fin des années 1960 que l'historien marxiste Éric J. Hobsbawm renouvelle en profondeur l'étude du brigandage à travers deux ouvrages, l'un portant sur les "primitifs de la révolte", l'autre sur différentes figures de bandits de l'époque moderne et contemporaine ${ }^{8}$. Il brosse le portrait du «bandit social» qui n'est pas un simple criminel, même si les autorités le réduisent à cette dimension. Ce personnage appartient à « un groupe qui a recours à la violence et pratique le vol à main armée ", mais son comportement le rattache aux nombreuses expressions de révoltes du monde rural. Le brigand social ne s'attaque pas aux paysans pauvres, parmi lesquels il vit. Une injustice est le plus souvent à l'origine de sa rupture avec la société et les périodes de crises rurales suscitent un banditisme chronique dans les sociétés préindustrielles. Le brigandage exprime tout à la fois le refus d'une autorité centralisée qui semble illégitime et les changements impulsés par 
les autorités centrales. Homme jeune, doté d'une forte personnalité, le brigand fait alors figure de rebelle et peut exprimer les refus de tout un groupe social, incarnant la résistance de la société rurale face aux prétentions autoritaires de l'État.

Les archives de la période moderne confirment l'existence de ce type de brigandage tout en introduisant d'importantes nuances montrant que le brigandage social n'en épuise pas toutes les formes. Au cours des nombreuses révoltes paysannes contre la fiscalité et les progrès de l'absolutisme royal en France au XVII ${ }^{e}$ siècle, contestation paysanne et brigandage se mêlent parfois de manière complexe. C'est souvent à l'occasion de ces insurrections que sont nommés les intendants, dont la mission consiste à veiller à l'établissement de l'ordre voulu par le pouvoir central dans les provinces. Disposant de la force armée, l'intendant parvient le plus souvent à écraser les paysans révoltés, mais il arrive que la répression conduise à une mutation de la contestation plus qu'à son éradication. C'est le cas, par exemple, lors de la révolte des Croquants à la fin des années $1630^{\circ}$. Entrées dans une dynamique insurrectionnelle en 1637 , les paroisses sont progressivement désarmées, mais une partie des rebelles refuse d'abandonner la lutte. Réfugiés dans des bois aux portes de Périgueux en 1640, ces hommes attaquent les convois, les marchands et les riches citadins. La ville est considérée comme le relais de l'autorité royale et, par ailleurs, elle est exemptée d'une bonne partie de la fiscalité royale directe, source des révoltes antifiscales qui ponctuent le règne de Louis XIII. L'armée est à ce point impuissante face aux brigands que la seule issue a semblé d'abattre la forêt tout entière, tâche que les soldats n'ont pu mener à bien.

5 Un siècle plus tard, Mandrin gagne sa popularité sur des bases assez proches: il s'oppose à l'État central en pratiquant la contrebande et ridiculise les forces militaires déployées contre lui en leur échappant plusieurs années durant. Par ailleurs, ce «brigand» n'attaque jamais les populations paysannes. Au cours du XvIII siècle, la contrebande se développe dans nombre de régions frontalières ou montagneuses (Provence, Dauphiné, Pyrénées, Flandres, Rhénanie...). Cette activité peut occuper des familles ou des villages entiers. La question soulevée par la contrebande est celle de la légitimité de la fiscalité imposée par l'État central aux populations ainsi que celle des forces de l'ordre déployées sur le territoire. Malgré la faiblesse de leurs effectifs, elles sont tout aussi violemment rejetées que les impôts par les populations rurales. Ces traits sont encore plus marqués dans les régions où les communautés arbitrent ellesmêmes les conflits et maintiennent l'ordre. L'intervention des forces de l'ordre de la monarchie est alors vécue comme une violation des droits et coutumes constitutifs de l'identité locale. C'est pourquoi les villageois dénoncent rarement les brigands, surtout s'ils pratiquent la contrebande. Tout au long de l'époque moderne, cette complicité est considérée par les autorités comme un véritable fléau, cause première de l'échec dans la lutte contre le brigandage. Sous la Révolution, les communes seront rendues responsables des actes de brigandage commis sur leur territoire par la loi du 10 vendémiaire an IV. Il s'agit d'obliger les villageois à rompre avec la loi du silence qui protège les brigands depuis des siècles.

6 Les historiens de l'époque moderne ont interrogé le brigandage à travers une grille de questionnement complexe, mettant en valeur les formes de délinquance, l'insertion de la contrebande dans une économie parallèle, mais aussi les caractères politiques $d u$ brigand perçu comme un rebelle. Le temps des guerres de religion introduit beaucoup de confusion dans l'appréhension du brigandage. Le comportement violent des 
seigneurs qui conduisent des troupes souvent hétérogènes et indisciplinées pousse les victimes à parler de brigandages à leur propos. Les massacres, les violences contre les populations, la politique de la terre brûlée et des pillages, tout pousse à cette confusion. On constate cependant que les sources de l'époque attribuent le qualificatif de «brigand » aux capitaines et aux soldats de l'autre confession. On peut y lire la volonté de discréditer l'ennemi et pas seulement de décrire une dérive de la violence religieuse. Cette attitude se retrouve au moment de la guerre des Camisards au début du XVIII siècle. Les bandes rebelles qui suivent les «prophètes » cévenols sont des "guerriers de Dieu » pour les uns, des brigands pour les autres. La volonté de dénigrement et de disqualification de la lutte est nette et sanctionne aussi le caractère populaire des insurgés.

7 Confrontées à un processus de normalisation des comportements sociaux, voulu par l'État et par les Églises, les populations ont également souffert d'une pression fiscale accrue dans un contexte de crise prolongée sur la longue durée (xvII $-\mathrm{xVIII}{ }^{\mathrm{e}}$ siècle). L'inflation du nombre des pauvres (environ $30 \%$ de la population), des mendiants et des errants, l'omniprésence de la guerre et des troupes sur le territoire ont contribué à renforcer un sentiment d'insécurité qui tient aussi aux attaques sourdes portées contre la civilisation paysanne traditionnelle ${ }^{10}$. L'exemple le plus abouti est sans doute celui des bandits Corses de la fin du XvIII ${ }^{\mathrm{e}}$ siècle $^{11}$. Un officier du régiment de Picardie en poste dans l'île écrit à ce propos : «Le terme bandit n'a pas ici en Corse la même signification qu'en France. On y appelle de ce nom tout Corse qui ne veut ni reconnaître [sic] ni se soumettre au gouvernement reçu ». Le bandit est un résistant qui refuse la conquête et lutte pour la Corse indépendante, mais il agit également dans le cadre d'une province en proie à une double violence, celle, endogène, des villageois et celle de l'État qui punit ici bien plus sévèrement qu'en France. Les historiens sont cependant unanimes à constater une mutation en profondeur de la délinquance à la fin de l'Ancien régime. On a longtemps affirmé que la violence populaire s'était atténuée à la fin du siècle des Lumières, que les crimes de sang étaient moins nombreux et moins sauvages. En réalité, il n'y a pas eu recul de la protestation populaire mais plutôt mutation: les révoltes sont moins massives mais plus fréquentes, moins sanglantes mais tout aussi violentes. Jean Nicolas a montré combien cette évolution a fait glisser la France dans un contexte de grande insécurité, très largement sous-estimée pour la fin de l'Ancien régime $^{12}$. L'explosion de la Grande Peur de l'été 1789 trouve place dans une suite cohérente de peurs et d'angoisse sociale liées à la poussée de la misère, du vagabondage et de la violence à la veille de la Révolution Française.

8 Les hommes de 89 veulent fonder une société nouvelle, reposant sur un ordre plus juste et une approche humaniste de la justice. La répression de la criminalité a fait l'objet de toute l'attention des législateurs qui ont confié l'exercice de la justice a des citoyens élus et non plus à des professionnels. Confrontés à une montée des violences politiques et sociales, ces juges ont bien du mal à affronter un brigandage qui surgit massivement au lendemain de la mort de Robespierre dans un contexte de réaction royaliste paroxystique dans les départements du Midi. Oscillant entre des amnisties censées ramener la paix sociale et des lois aggravant la répression dans les zones rurales, la Révolution est confrontée à la difficulté de caractériser pénalement le brigandage. Les bandes de chouans dans l'Ouest, les brigands royaux dans le Midi sont-ils des opposants politiques ou des criminels? Encore une fois se mêlent des comportements qui relèvent de la criminalité de droit commun (vols sur les grands chemins, vols commis en bandes 
dans les fermes isolées, assassinats, viols) et de la politique, lorsque les voleurs ne s'attaquent qu'aux caisses de l'État, aux recettes fiscales, aux biens des patriotes ou à leur personne. Les sources révolutionnaires attestent une poussée très forte du brigandage, ce qui doit nous conduire à accorder une attention particulière au contexte historique et non pas à une nature "éternelle " et intrinsèque du brigandage. Les brigands sont le fruit de leur époque, ne serait-ce que parce que l'usage du terme «brigand » est, de tout temps, très fortement connoté. Si ce terme est le plus souvent utilisé pour dénigrer, il est aussi porteur de valeurs positives autour de l'idée de force, de puissance, de courage. Ainsi, les patriotes avignonnais qui, en 1791, se baptisent euxmêmes les «braves brigands de l'armée du Vaucluse » revendiquent l'usage d'une violence sauvage au service d'une "cause", celle du rattachement à la France. L'ambiguité du terme brigand reste donc très forte sous la Révolution et le Consulat. L'éradication, même relative, de cette forme de délinquance sous l'Empire et la Restauration ne met pas un terme à la fonction sociale de l'image du brigand dont s'empare la littérature romantique, qui met en scène des hommes violents et brutaux, familiers des espaces ensauvagés, mais aussi rebelles, résistants et justiciers. Cette image, reflet des contradictions portées par les brigands de l'époque moderne, se perpétue jusqu'à nos jours à travers la figure des membres de la bande à Bonnot, de Carlos ou de Mesrine dont le cinéma s'est fait l'écho. Le brigand occupe donc encore une place de choix dans le panthéon des représentations collectives, non dépourvues d'une ambiguïté qui s'avère l'un des traits fondamentaux du brigandage.

\section{NOTES}

1. A. FURETIERE, Dictionnaire universel, 1688-1689.

2. Dictionnaire GODEFROY, Dictionnaire de l'ancienne langue française et de tous ses dialectes $d u \mathrm{XI}^{e}$ au XV $\mathrm{V}^{e}$ siècle, Paris, 1881 ; Dictionnaire LAROUSSE du Moyen Français.

3. Dictionnaire universel français et latin..., 1704-1771, Articles « brigand » et « bandi ».

4. D. TeRnoIs, Jacques Callot : catalogue complet de son œuvre dessiné, Paris, F. de Nobele, 1962, 614 p.

5. P. PEVERI, "La criminalité cartouchienne : vols, voleurs et culture criminelle dans le Paris de la Régence", in L. ANDRIES, Cartouche, Mandrin et autres brigands du XVIII ${ }^{e}$ siècle, Paris, Desjonquères, 2010.

6. On peut donner pour exemple les travaux de F. FUNCK-BRENTANO, Les brigands, Paris, Hachette, 1905.

7. M. MARION, Le brigandage pendant la Révolution, Paris, Plon, 1934.

8. Е. J. НовSBAWм, Les Primitifs de la révolte dans l'Europe moderne, Paris, Fayard, 1963 (éd. originale : Primitive Rebels, 1959) ; id., Les bandits, Londres, 1969, Paris, Maspéro, 1972.

9. Y.-M. BERCÉ, Histoire des croquants, Paris, Éditions du Seuil, 1986.

10. Je renvoie sur ce thème aux travaux de R. MUCHEMBLED, et notamment à : La violence au village. Sociabilité et comportements populaires en Artois au XV siècle, Turnhout, Brépols, 1989 et à : Le temps des supplices. De l'obéissance sous les rois absolus, XV'-XVIII siècle, Paris, Armand Colin, 1992, rééd. Pocket, 2005. 
11. Banditisme et violence sociale dans les sociétés de l'Europe méditerranéenne, Actes du colloque de Bastia (27-29 mai 1993), Textes réunis par G. RAVIS-GIODANI et A. Rovere, Ajaccio, La Marge, 1997, p. 261-267.

12. J. Nicolas, La rébellion française. Mouvements populaires et conscience sociale 1661-1789, Paris, Éditions du Seuil, 2002.

\section{AUTEUR}

\section{VALÉRIE SOTTOCASA}

Maître de Conférences d'histoire moderne

Université de Toulouse (UTM)

FRAMESPA - UMR 5136

valerie.sottocasa@wanadoo.fr 